\title{
Burden of comorbidities among Japanese patients with atrial fibrillation: a case study of dyspepsia
}

This article was published in the following Dove Press journal:

Clinical and Experimental Gastroenterology

18 May 2013

Number of times this article has been viewed

\author{
Yoshikazu Kinoshita' \\ Marco DiBonaventura ${ }^{2}$ \\ Bruno Rossi ${ }^{3}$ \\ Kazuya Iwamoto ${ }^{4}$ \\ Edward CY Wang 5 \\ Jean-Baptiste Briere \\ 'Department of Gastroenterology \\ and Hepatology, Shimane University \\ School of Medicine, Izumo, Japan; \\ ${ }^{2}$ Health Sciences Practice, Kantar \\ Health, New York, NY, USA; \\ ${ }^{3}$ Market Access, ${ }^{4}$ Medical Affairs \\ Cardiovascular and Neurology, \\ ${ }^{5} \mathrm{Health}$ Economics and Outcomes \\ Research, Bayer Yakuhin Ltd, Osaka, \\ Japan
}

Background: The aim of this study was to investigate the link between atrial fibrillation (AF) and dyspepsia, as well as the contribution of dyspepsia to the overall burden of AF.

Methods: The 2008, 2009, and 2010 Japan National Health and Wellness Survey (NHWS) datasets were used in this study. The NHWS is an Internet-based survey administered to the adult population in Japan using a random stratified sampling framework to ensure demographic representativeness. The presence of dyspepsia was compared between those with and without AF. Among those with AF, the effect of dyspepsia on health status, work productivity, and activity impairment was examined, along with health care resource use using multivariable regression modeling and controlling for baseline differences.

Results: Among patients with AF ( $\mathrm{n}=565)$, the three most commonly reported comorbidities were hypertension (38.76\%), dyspepsia (37.35\%), and overactive bladder (28.72\%). Patients with AF had $48.59 \%$ greater odds of reporting dyspepsia than those without AF $(P<0.05)$. Patients with dyspepsia used more AF medications (2.05 versus 1.54$)$ and had been diagnosed more recently (9.97 versus 10.58 years). Dyspepsia was associated with significantly worse physical health status $(P<0.05)$ and significantly more absenteeism, overall work impairment, activity impairment, physician visits, and emergency room visits (all $P<0.05$ ).

Conclusion: Patients with AF in Japan experience a number of comorbidities, with dyspepsia being the most common noncardiovascular comorbidity. Given the prevalence and additional burden of this comorbidity across both humanistic and economic outcomes, the management of dyspepsia among patients with AF should be an area of greater focus.

Keywords: atrial fibrillation, dyspepsia, health status, work productivity, health care resource use

\section{Introduction}

Atrial fibrillation (AF) is the most common cardiac arrhythmia, affecting approximately $0.65 \%$ of the Japanese population. ${ }^{1}$ Its presence is associated with a significant increase in future stroke risk. ${ }^{2}$ Aside from elevated stroke risk, AF is associated with a substantial burden on both the patient and society. According to previous literature, nearly all domain scores of the Short-Form 36 (a measure of health status) were significantly lower in patients with AF compared with age-matched controls. ${ }^{3,4}$ In the United States, direct costs ranged from $\$ 2000$ to $\$ 14,200$ per patient per year, predominantly because of an increased number of hospitalizations. ${ }^{5}$ Lastly, patients with AF who remain in the work force also have significantly more sick leave and short-term disability than non-AF controls. ${ }^{6}$

Although primarily linked to the disease itself, the patient burden can be exacerbated by the presence of comorbidities. Indeed, patients with AF experience
Correspondence: Marco DiBonaventura Health Sciences Practice, Kantar Health, II Madison Avenue, 12th Floor,

New York, NY I0010, USA

$\mathrm{Tel}+\mathrm{I} 2127063988$

Fax +I 2126477659

Email marco.dibonaventura@

kantarhealth.com 
a number of concomitant conditions. Although the prevalence of cardiovascular comorbidities among Japanese patients with $\mathrm{AF}^{7-9}$ as well as the effect of these comorbidities with respect to health-related quality of life, have already been investigated, ${ }^{10}$ information on other comorbidities is scarce. In the United States, LaMori et al found that 34\% of patients with AF also reported experiencing dyspepsia, and that the presence of dyspepsia among patients with AF was associated with a significant decrease in health status and a significant increase in health care resource utilization and work productivity loss. ${ }^{11}$

Given that the characteristics of Japanese AF patients have been reported to differ from other populations, including a lower body weight and a more dramatic gender split, ${ }^{9}$ it is important to extend prior research by investigating the prevalence and effect of dyspepsia in Japan rather than extrapolating data from other countries. The objectives of the current study were, firstly, to clarify the link between AF and dyspepsia and, secondly, to understand the attributable burden of dyspepsia among patients with AF in Japan.

\section{Materials and methods}

\section{Data source}

The current study used data from the 2008, 2009, and 2010 Japan National Health and Wellness Surveys (NHWS, Kantar Health, New York, NY, USA). Details on the Japan NHWS are provided elsewhere. ${ }^{12}$ In brief, the NHWS is a large, nationally representative, cross-sectional, Internetbased health survey of adults aged 18 years or older. Potential respondents are recruited through a stratified random sampling framework to ensure that the demographic composition is representative of the total Japanese adult population. ${ }^{12}$ Because it is possible for a respondent to complete the NHWS more than once over this three-year period, a small subset of 2008 respondents also completed the survey in 2009 and 2010. Similarly, a small subset of 2009 respondents also completed the survey in 2010. In these instances, only the most recent data points for each respondent were included. A total of 60,015 unique respondents who completed the 2008, 2009, or 2010 Japan NHWS were included in the analyses.

\section{Measures}

\section{Atrial fibrillation}

All NHWS respondents were presented with a list of medical comorbidities and asked to select which conditions they had ever experienced (AF was one of these conditions, presented as "atrial fibrillation", although the specific type of AF the respondents had experienced was not assessed). For the conditions selected, respondents were then asked whether they had been formally diagnosed ("yes" versus "no"). Only respondents who reported having been diagnosed with AF were considered to have AF. No exclusion criteria were applied.

\section{Dyspepsia}

The NHWS did not include a direct assessment of dyspepsia. As a result, we used a proxy measure of dyspepsia based on the presence of conditions that share symptoms with, and are often associated with, functional dyspepsia. These conditions included ulcers, abdominal bloating, abdominal pain, gastroesophageal reflux disease (GERD), and heartburn. Patients who self-reported any of those conditions were considered to have dyspepsia. The same approach to assessing dyspepsia has been used in prior research. ${ }^{11}$

\section{Demographics}

Age (18-39, 40-49, 50-59, 60-69, 70 years and older), gender (male versus female), education (college-educated versus less than college-educated), employment (currently employed versus not employed), and annual household income ( $<¥ 3,000,000, ¥ 3,000,000$-4,999, 999, $¥ 5,000,000$ $7,999,999$, $\geq ¥ 8,000,000$, or declined to answer) were included.

\section{Patient characteristics}

Smoking (currently a smoker versus former smoker versus never smoked), alcohol use (currently drinking versus not currently drinking), exercise (currently exercising versus not currently exercising), bodyweight (in kilograms), and body mass index (underweight, normal weight, overweight, obese, decline to answer) were assessed for all respondents. The Charlson comorbidity index ${ }^{13}$ was calculated based on self-reported comorbidities.

\section{Disease history}

Location of AF diagnosis, years diagnosed with AF, AF treatment (neither acetylsalicylic acid [ASA] nor warfarin, ASA without warfarin, ASA and warfarin, warfarin without ASA) and symptom severity were included. The total number of medications taken for AF was also summed and reported.

\section{Health outcomes}

The Japanese version of the Medical Outcomes Study 12-Item Short-Form Survey Instrument was used as a generic health status instrument. ${ }^{14,15}$ Physical component summary 
and mental component summary scores along with health utilities (SF-6D) were included in the analysis, with higher scores indicating better health status. Physical and mental component summary scores each vary between 0 and 100 , with the population mean set at 50 . Health utilities vary on a theoretical scale between 0 and 1 , with 0 indicating a health state associated with death, and 1 indicating a health state associated with perfect health. The general health version of the Work Productivity and Activity Impairment questionnaire was used to assess absenteeism (the percentage of work time missed because of one's health in the past seven days), presenteeism (the percentage of impairment experienced while at work in the past seven days because of one's health), overall work productivity loss (an overall impairment estimate that is a combination of absenteeism and presenteeism), and activity impairment (the percentage of impairment in daily activities because of one's health in the past seven days). ${ }^{16}$ Only respondents who reported being full-time, part-time, or self-employed provided data for absenteeism, presenteeism, and overall work impairment. All respondents provided data for activity impairment. The number of physician visits, emergency room visits, and hospitalizations in the previous six months were also reported by all respondents.

\section{Statistical analysis}

The prevalence of dyspepsia among those with and without AF was compared using a Chi-square test. The presence of dyspepsia was then predicted from the presence of $\mathrm{AF}$ in a logistic regression model controlling for age, gender, education, household income, body mass index, smoking status, exercise behavior, and comorbidities via the Charlson comorbidity index.

Among those with AF only, differences between patients with and without dyspepsia were examined for demographics, patient characteristics, and disease history using Chi-square tests and independent-samples $t$-tests for categorical and continuous variables, respectively. Adjusted differences between those with and without dyspepsia with regard to health outcomes were assessed using general linear models (for health status) and generalized linear models (for work productivity and health care resource use). The latter models (specifying a negative binomial distribution and a $\log$ link function) were used to handle the inherent skewness of those variables correctly. All multivariable regression models controlled for the number of medications and the years diagnosed, because these were the only variables that were significantly different between those with and without dyspepsia and significantly predictive of health outcomes.
The a priori cutoff for statistical significance of predictors in the regression model was set at $P<0.05$.

\section{Results}

A total of 565 patients $(0.94 \%)$ reported a diagnosis of AF. Among these patients, the five most commonly reported comorbidities were hypertension (38.76\%), dyspepsia $(37.35 \%)$, overactive bladder $(28.72 \%)$, high cholesterol (17.88\%), and angina pectoris (16.81\%), making dyspepsia the most common non-cardiovascular comorbidity. Among those with AF, the components of dyspepsia included heartburn (15.58\%), abdominal pain (12.57\%), abdominal bloating (9.03\%), GERD (8.67\%), and ulcers (8.50\%), with $37.16 \%$ of patients having at least two of those component conditions.

The prevalence of dyspepsia was significantly higher in those with AF (37.35\%) than in the general adult population without AF from NHWS $\left(21.30 \% ; \chi^{2}[1]=85.51\right.$, $P<0.0001)$. Even after adjusting for sociodemographics, health behaviors, and comorbidities, patients with AF had $48.59 \%$ greater odds of reporting dyspepsia than those without AF $(\mathrm{b}=0.40$, odds ratio $=1.49, P<0.0001$, see Table 1).

Among those with AF, patients with comorbid dyspepsia were similar to those without AF on all demographic variables (see Table 2). The distributions of age, gender, education, employment, and household income between these two groups were the same (all $P>0.18$ ). Similarly, no differences between those with and without dyspepsia were observed with respect to patient characteristics. Distributions of body mass index, bodyweight, smoking status, alcohol use, and exercise behavior were similar between AF patients with and without dyspepsia (all $P>0.05$ ).

However, a few differences were observed with respect to AF-related history. Patients with dyspepsia were more likely to have been diagnosed in a hospital (78.67\% versus $70.34 \%$ ) and less likely to have been diagnosed in a physician's office (13.74\% versus $21.19 \%$, see Table 3 ). Patients with dyspepsia also reported having been diagnosed more recently $(9.97$ versus 10.58 years, $P=0.005$ ) and reported using significantly more AF medications (2.05 versus $1.54, P<0.001)$.

Prior to covariate adjustment, the health outcomes of those with AF (without regard to dyspepsia) were compared with those with AF but without dyspepsia, and with those having AF as well as dyspepsia (see Table 4). All health outcomes were worse among those with comorbid dyspepsia, including health status, work productivity loss, activity impairment, and health care resource use. 
Table I Logistic regression model predicting the presence of dyspepsia

\begin{tabular}{|c|c|c|c|c|c|c|c|}
\hline & $\mathbf{b}$ & SE b & $\chi^{2}$ & $P$-value & OR & $\begin{array}{l}\text { OR } \\
95 \% \text { LCL }\end{array}$ & $\begin{array}{l}\text { OR } \\
95 \% \text { UCL }\end{array}$ \\
\hline Intercept & -1.307 & 0.056 & 542.175 & $<0.0001$ & & & \\
\hline Age & 0.005 & 0.001 & 44.408 & $<0.0001$ & 1.005 & 1.003 & 1.006 \\
\hline Male & -0.277 & 0.024 & I34.848 & $<0.0001$ & 0.758 & 0.723 & 0.794 \\
\hline University education & -0.051 & 0.022 & 5.477 & 0.0193 & 0.95 & 0.91 & 0.992 \\
\hline Annual income: $<¥ 3$ million & 0.022 & 0.032 & 0.474 & 0.4913 & $\mathrm{I} .023$ & 0.96 & 1.09 \\
\hline Annual income: $¥ 3$ to $<¥ 5$ million & - & - & - & - & - & - & - \\
\hline Annual income: $¥ 5$ to $<¥ 8$ million & 0.075 & 0.029 & 6.856 & 0.0088 & 1.077 & 1.019 & 1.139 \\
\hline Annual income: $¥ 8$ million or more & 0.068 & 0.030 & 5.324 & 0.021 & $\mathrm{I} .07 \mathrm{I}$ & 1.01 & 1.135 \\
\hline Annual income: declined to answer & -0.111 & 0.041 & 7.321 & 0.0068 & 0.895 & 0.826 & 0.97 \\
\hline BMI: underweight & 0.042 & 0.032 & 1.714 & 0.1905 & 1.043 & 0.979 & I.II \\
\hline BMI: normal weight & - & - & - & - & - & - & - \\
\hline BMI: overweight & 0.149 & 0.028 & 27.821 & $<0.0001$ & 1.16 & 1.098 & 1.226 \\
\hline BMI: obese & 0.292 & 0.061 & 23.131 & $<0.0001$ & 1.34 & 1.189 & 1.509 \\
\hline BMI: missing & -0.198 & 0.069 & 8.216 & 0.0042 & 0.82 & 0.716 & 0.939 \\
\hline Never smoked & -0.536 & 0.026 & 418.242 & $<0.0001$ & 0.585 & 0.556 & 0.616 \\
\hline Former smoker & -0.051 & 0.028 & 3.418 & 0.0645 & 0.95 & 0.9 & 1.003 \\
\hline Current smoker & - & - & - & - & - & - & - \\
\hline Currently exercise & 0.065 & 0.021 & 9.493 & 0.0021 & 1.067 & $\mathrm{I} .024$ & 1.111 \\
\hline Charlson comorbidity index & 0.959 & 0.023 & I737.784 & $<0.000$ I & 2.609 & 2.494 & 2.729 \\
\hline Atrial fibrillation & 0.396 & 0.095 & 17.294 & $<0.0001$ & 1.486 & 1.233 & 1.792 \\
\hline
\end{tabular}

Abbreviations: BMI, body mass index; OR, odds ratio; LCL, lower confidence limit; UCL, upper confidence limit; SE, standard error of measurement.

This pattern remained even after controlling for differences in disease history (see Figure 1). Patients with dyspepsia reported significantly lower levels of physical component summary scores $(41.32$ versus $45.66, P<0.0001)$ and health state utilities $(0.70$ versus $0.76, P=0.008)$. Although a trend for lower mental component summary scores was found (48.51 versus 50.33, $P=0.09$ ), this difference was not statistically significant.

Among those who were employed, a significant effect of dyspepsia on work productivity was also observed (see Figure 2). Those with dyspepsia reported significantly more absenteeism $(11.77 \%$ versus $1.33 \%, P=0.003)$ and overall work impairment, which included both absenteeism and presenteeism $(26.65 \%$ versus $17.02 \%, P=0.045)$. Although a trend for higher presenteeism was found $(24.39 \%$ versus $15.28 \%, P=0.10$ ), this difference was not statistically significant. Among all patients with AF, not just those employed, patients with dyspepsia reported significantly higher levels of impairment in daily activities $(29.27 \%$ versus $23.07 \%, P=0.036$ ).

The presence of dyspepsia was also associated with direct cost drivers (see Figure 3). Indeed, patients with dyspepsia reported significantly more physician visits (19.35 versus $12.62, P=0.0003)$ and significantly more emergency room visits $(0.40$ versus $0.14, P=0.008)$ in the past six months than those without dyspepsia. Although the number of hospitalizations was higher (3.27 versus $1.73, P=0.13$ ), this difference was not statistically significant between the two groups.

\section{Discussion}

As reported previously, ${ }^{9}$ patients with AF in Japan suffer from a number of comorbidities, with cardiovascular, urological, and gastrointestinal conditions each being reported by more than one third of AF patients. Our results demonstrate that, when looking at individual conditions, dyspepsia is the most common non-cardiovascular comorbidity, reported by $37.35 \%$ of AF patients. Indeed, it is significantly more likely that patients with $\mathrm{AF}$ will have dyspepsia compared with patients without AF. It is difficult to compare these point estimates with previous reports, because few studies have assessed the Japanese population, and definitions of dyspepsia vary considerably. However, these statistics do largely coincide with prior research. For example, Mahadeva et al reported that $24.3 \%$ of the general population of Kuala Lumpur suffered from dyspepsia (defined as upper abdominal discomfort occurring for at least three weeks in the previous 12 months) compared with $21.3 \%$ of the general population in NHWS. ${ }^{17}$ Prior research from the West has suggested that GERD symptoms occur in $20 \%-25 \%$ of those with dyspepsia (regardless of AF status) which is higher than what was observed in our study (15.28\% for heartburn and $8 \%$ for GERD). ${ }^{18-20}$ 
Table 2 Differences in demographic and lifestyle characteristics between AF patients with and without comorbid dyspepsia

\begin{tabular}{|c|c|c|c|c|c|}
\hline & \multicolumn{2}{|c|}{$\begin{array}{l}\text { Dyspepsia } \\
(n=2 I I)\end{array}$} & \multicolumn{2}{|c|}{$\begin{array}{l}\text { No dyspepsia } \\
(n=354)\end{array}$} & \multirow[t]{2}{*}{$P$-value } \\
\hline & $\mathbf{n}$ & $\%$ & $\mathbf{n}$ & $\%$ & \\
\hline Age, years & & & & & 0.3137 \\
\hline $18-39$ & 12 & 5.69 & 12 & 3.39 & \\
\hline $40-49$ & 16 & 7.58 & 16 & 4.52 & \\
\hline $50-59$ & 29 & 13.74 & 45 & $|2.7|$ & \\
\hline $60-69$ & 71 & 33.65 & 140 & 39.55 & \\
\hline$\geq 70$ & 83 & 39.34 & $14 \mid$ & 39.83 & \\
\hline Gender & & & & & 0.7676 \\
\hline Male & 175 & 82.94 & 297 & 83.90 & \\
\hline Female & 36 & 17.06 & 57 & 16.10 & \\
\hline Education & & & & & 0.4046 \\
\hline Less than university education & 74 & 35.07 & 112 & 31.64 & \\
\hline University education & 137 & 64.93 & 242 & 68.36 & \\
\hline Employment & & & & & 0.6083 \\
\hline Unemployed & 138 & 65.40 & 239 & 67.51 & \\
\hline Currently employed & 73 & 34.60 & 115 & 32.49 & \\
\hline Annual household income & & & & & 0.1782 \\
\hline$<¥ 3$ million & 32 & 15.17 & 67 & 18.93 & \\
\hline$¥ 3$ to $<¥ 5$ million & 72 & 34.12 & 128 & 36.16 & \\
\hline$¥ 5$ to $<¥ 8$ million & 42 & 19.91 & 82 & 23.16 & \\
\hline$¥ 8$ million or more & 45 & 21.33 & 49 & 13.84 & \\
\hline Declined to answer & 20 & 9.48 & 28 & 7.91 & \\
\hline Body mass index & & & & & 0.3266 \\
\hline Missing & 0 & 0.00 & I & 0.28 & \\
\hline Underweight & 15 & 7.11 & 21 & 5.93 & \\
\hline Normal & 136 & 64.45 & 254 & 71.75 & \\
\hline Overweight & 53 & 25.12 & 70 & 19.77 & \\
\hline Obese & 7 & 3.32 & 8 & 2.26 & \\
\hline Mean (SD) weight $(\mathrm{kg})$ & 64.89 & 11.19 & 64.15 & 10.79 & 0.8783 \\
\hline Smoking status & & & & & 0.1636 \\
\hline Never smoked & 60 & 28.44 & 115 & 32.49 & \\
\hline Former smoker & 102 & 48.34 & 180 & 50.85 & \\
\hline Current smoker & 49 & 23.22 & 59 & 16.67 & \\
\hline Alcohol use & & & & & 0.4239 \\
\hline Do not drink & 54 & 25.59 & 80 & 22.60 & \\
\hline Currently drink & 157 & 74.41 & 274 & 77.40 & \\
\hline Exercise behavior & & & & & 0.9099 \\
\hline Do not exercise & 86 & 40.76 & 146 & 41.24 & \\
\hline Currently exercise & 125 & 59.24 & 208 & 58.76 & \\
\hline Mean (SD) CCl & 1.46 & 4.72 & 0.35 & 0.69 & 0.1162 \\
\hline
\end{tabular}

Note: Within-variable categories may not sum to exactly $100 \%$ due to rounding.

Abbreviations: $\mathrm{AF}$, atrial fibrillation; $\mathrm{CCl}$, Charlson comorbidity index; $\mathrm{SD}$, standard deviation.

However, Mahadeva et al found that these symptoms were far less common for dyspepsia among Southeast Asian populations than those from the West, suggesting that our lower estimates may be in the range of what would be expected in a Japanese population. ${ }^{21}$

Although prior studies have not examined the link between AF and dyspepsia specifically, our findings are consistent with the literature examining the link between $\mathrm{AF}$ and GERD, ${ }^{22-24}$ a condition frequently associated with functional dyspepsia and sharing commonalities with the symptom experience (eg, epigastric pain/burning). ${ }^{25} \mathrm{Kunz}$ et al have found GERD to be a risk factor for $\mathrm{AF}^{22}$ and other studies have shown GERD to have a potential role in the pathogenesis of paroxysmal AF. ${ }^{23,24}$

Interestingly, few demographic and patient history differences were observed between those with and without dyspepsia, making it difficult to anticipate patients who may be more susceptible to this condition. The presence of dyspepsia was indifferent to gender, age, bodyweight, overall comorbidity profile, and health risk behaviors, such as 
Table 3 Differences in disease history between AF patients with and without comorbid dyspepsia

\begin{tabular}{|c|c|c|c|c|c|}
\hline & \multicolumn{2}{|c|}{$\begin{array}{l}\text { Dyspepsia } \\
(n=2 I I)\end{array}$} & \multicolumn{2}{|c|}{$\begin{array}{l}\text { No dyspepsia } \\
(n=354)\end{array}$} & \multirow[t]{2}{*}{$P$-value } \\
\hline & $\mathbf{n}$ & $\%$ & $\mathbf{n}$ & $\%$ & \\
\hline Location of diagnosis & & & & & 0.0187 \\
\hline Unknown & II & 5.21 & 13 & 3.67 & \\
\hline Hospital & 166 & 78.67 & 249 & 70.34 & \\
\hline Physician's office & 29 & 13.74 & 75 & 21.19 & \\
\hline Other & 5 & 2.37 & 17 & 4.80 & \\
\hline Severity of AF symptoms & & & & & 0.4961 \\
\hline Mild & 112 & 53.08 & 199 & 56.21 & \\
\hline Moderate & 64 & 30.33 & 115 & 32.49 & \\
\hline Severe & 26 & 12.32 & 33 & 9.32 & \\
\hline Not available & 9 & 4.27 & 7 & 1.98 & \\
\hline Current treatment & & & & & 0.6433 \\
\hline Untreated & 78 & 36.97 & 124 & 35.03 & \\
\hline Treated & 133 & 63.03 & 230 & 64.97 & \\
\hline Treatment group & & & & & 0.1109 \\
\hline Neither ASA nor warfarin & 128 & 60.66 & 226 & 63.84 & \\
\hline ASA only & 19 & 9.00 & 16 & 4.52 & \\
\hline ASA + warfarin & 6 & 2.84 & 4 & 1.13 & \\
\hline Warfarin only & 58 & 27.49 & 108 & 30.51 & \\
\hline Number of AF medications (mean, SD) & 2.05 & 2.56 & 1.54 & 0.87 & $<0.000$ I \\
\hline Years diagnosed (mean, SD) & 9.97 & 10.53 & 10.58 & 10.64 & 0.0048 \\
\hline
\end{tabular}

Note: Within-variable categories may not sum to exactly $100 \%$ due to rounding.

Abbreviations: ASA, acetylsalicylic acid; AF, atrial fibrillation; N/A, not available; SD, standard deviation.

smoking and alcohol use. These results suggest that dyspepsia is not restricted to any particular subgroup of patients with AF. However, the relationship with number of medications and presence of dyspepsia suggests that this comorbidity is preventable in certain cases. It is also possible, as discussed in prior studies, that cardiovascular comorbidities could be a contributing factor in the presence of dyspepsia. ${ }^{25,26}$ Further research is necessary to uncover the true mechanisms of the relationship between AF and dyspepsia.

Although AF itself can pose a burden on the patient and society, ${ }^{3-6}$ our results suggest that a significant part of this burden is due to dyspepsia. Indeed, patients with dyspepsia reported significantly worse health status and significantly more work impairment, primarily due to absenteeism. More health care resource use was also observed, primarily due to physician visits and emergency room visits. Collectively, these findings suggest that the presence of dyspepsia not only poses significant societal costs by affecting patients' daily functioning and work productivity, but also incurs great health care costs through its direct management or exacerbation of other conditions. These results have important clinical implications, in that although many factors should

Table 4 Unadjusted mean level of health outcomes among AF patients with and without comorbid dyspepsia

\begin{tabular}{|c|c|c|c|}
\hline & \multirow{2}{*}{$\begin{array}{l}\text { All patients with AF } \\
(n=565)\end{array}$} & \multicolumn{2}{|c|}{ Patients with AF } \\
\hline & & $\begin{array}{l}\text { Dyspepsia } \\
(n=2 I I)\end{array}$ & $\begin{array}{l}\text { No dyspepsia } \\
(n=354)\end{array}$ \\
\hline SF-I2: mental component summary score & 48.91 & 47.70 & 49.63 \\
\hline SF-12: physical component summary score & 44.66 & 42.19 & 46.13 \\
\hline SF-6D: health utility score & 0.73 & 0.69 & 0.76 \\
\hline Number of physician visits per 6 months & 14.24 & 19.27 & 11.23 \\
\hline Number of ER visits per 6 months & 0.28 & 0.56 & 0.12 \\
\hline Number of hospitalizations per 6 months & 2.06 & 3.09 & 1.45 \\
\hline Absenteeism \% & 4.98 & 8.66 & 2.64 \\
\hline Presenteeism \% & 20.82 & 27.61 & 16.52 \\
\hline Overall work impairment $\%$ & 23.26 & 32.24 & 17.55 \\
\hline Activity impairment \% & 26.41 & 30.81 & 23.79 \\
\hline
\end{tabular}

Abbreviations: AF, atrial fibrillation; ER, emergency room; SF, Short Form. 


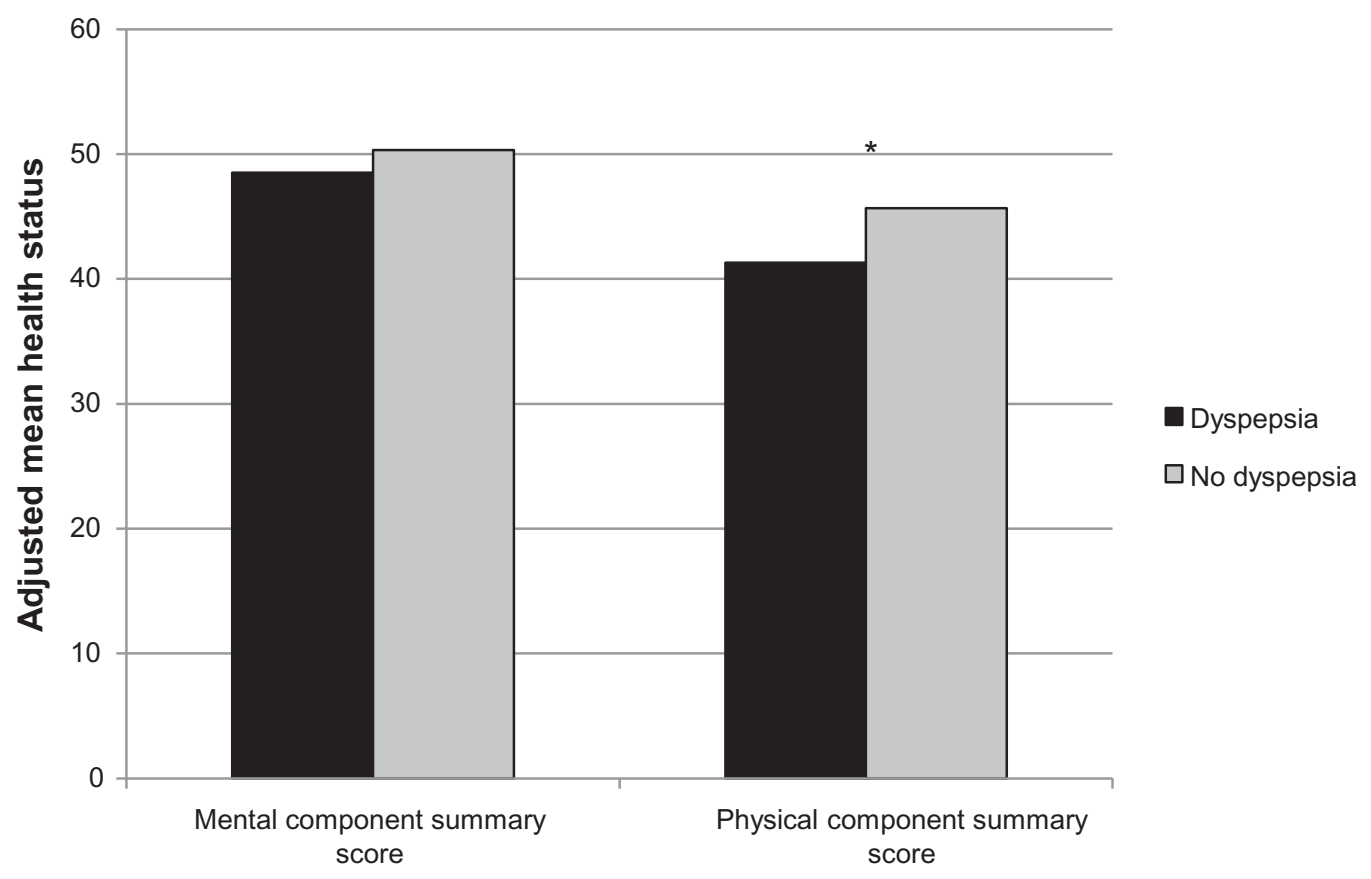

Figure I Adjusted mean health status (as measured by the Short-Form 12 version 2 instrument) between those with and without dyspepsia. Note: $* p<0.05$.

be considered when managing patients with AF, dyspepsia should not be overlooked.

\section{Limitations}

Several limitations of this research should be noted. The primary one is the definition of dyspepsia, which was determined using a proxy measure because direct assessment was not available in the NHWS data. Although the conditions used as part of the definition share symptoms with dyspepsia, and are often linked with the condition, it is possible that patients with these symptoms did not experience true dyspepsia and patients without these conditions

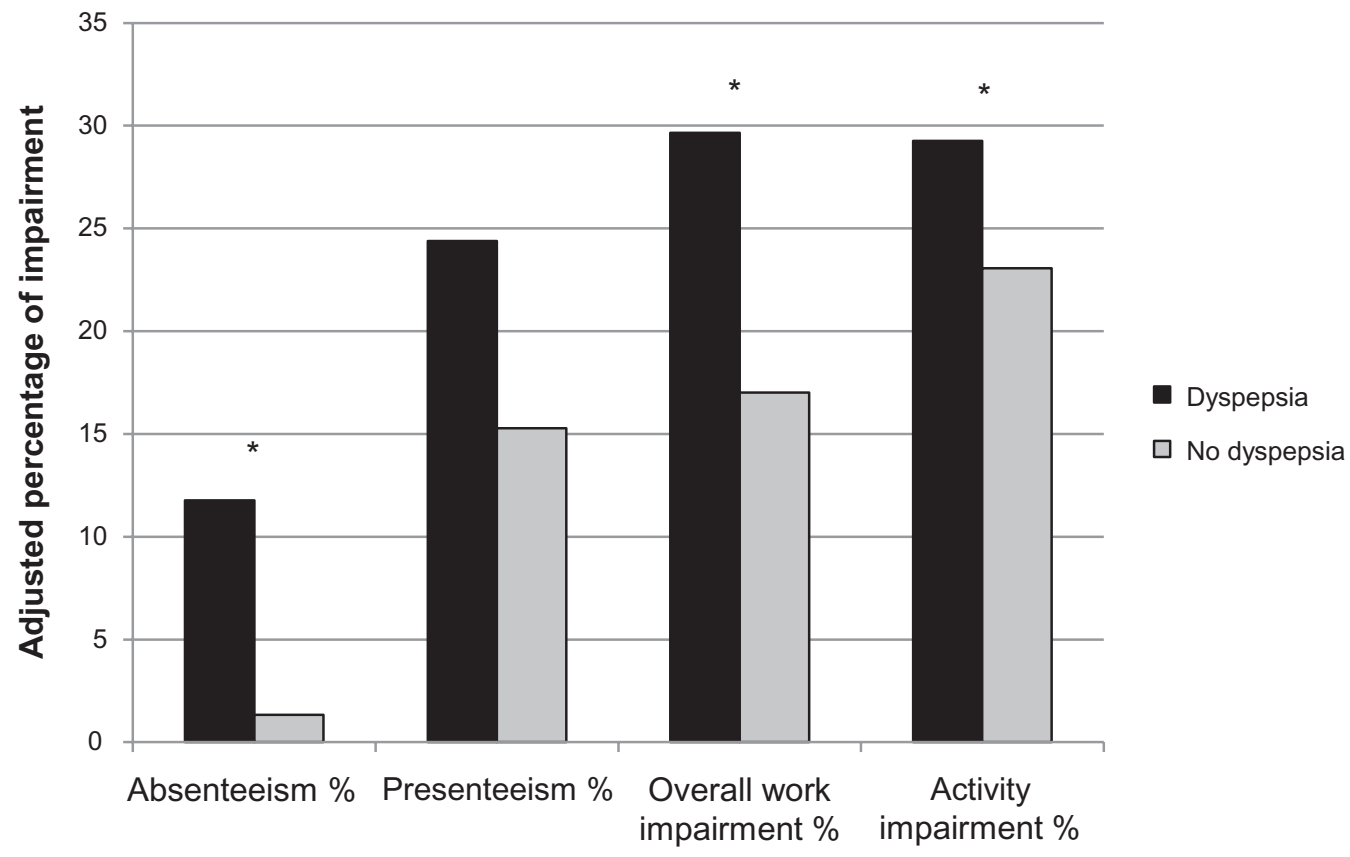

Figure 2 Adjusted percentage of impairment between those with and without dyspepsia. Note: $* P<0.05$. 


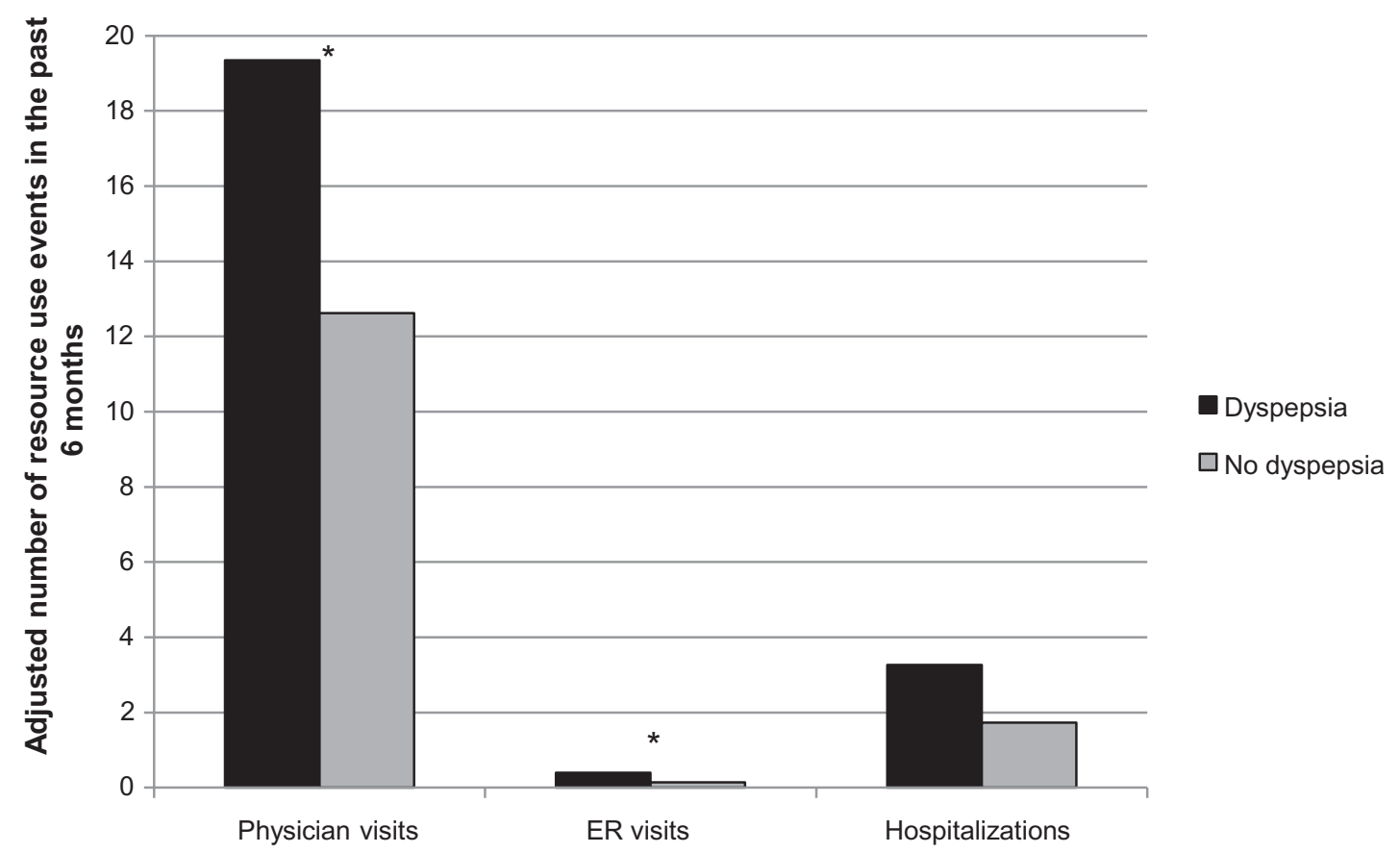

Figure 3 Adjusted number of health care resource use events in the past six months between those with and without dyspepsia. Note: $* P<0.05$.

did experience true dyspepsia. However, given the large number of patients (nearly $40 \%$ ) with at least two of these conditions, the relationship between our proxy measure and actual dyspepsia is likely to be very strong.

It should also be emphasized that all data from the NHWS were self-reported and no clinical verification of diagnoses or treatments were available. This could have introduced additional measurement error because patients may have mistakenly reported a diagnosis of $\mathrm{AF}$ and those without $\mathrm{AF}$ may have been undiagnosed. Related to this point, it should be noted that our prevalence of AF $(0.94 \%)$ was higher than that reported in the literature $(0.65 \%) .{ }^{1}$ The reason for this discrepancy is unclear, but it could be that it was more common to mistakenly report a diagnosis of AF than for those without $\mathrm{AF}$ to be undiagnosed. Future research would be necessary.

Because of the cross-sectional and observational nature of this study, the relationship between dyspepsia and health outcomes may not be causal. For example, some studies have suggested a link between depression and dyspepsia (although the causality of this relationship is also in question), which may explain some of the additional variability observed in the current study. No data on the type of AF (eg, paroxysmal) were available, which may have hidden underlying heterogeneity across AF subgroups.

Lastly, our findings may not be generalizable to the $\mathrm{AF}$ population in Japan. It is possible that the sample of patients with AF in the current study differs from the general AF population in Japan. The NHWS is nationally representative of the Japanese population with respect to age and gender, and the demographic characteristics of the sample of $\mathrm{AF}$ patients match those of prior publications. ${ }^{1,7,8,10}$ However, the extent to which those who decided to participate in the NHWS survey differ from the overall population of patients with $\mathrm{AF}$ is unknown.

\section{Conclusion}

In Japan, patients with AF experience a number of comorbidities, with dyspepsia being the most common noncardiovascular comorbidity. Few factors were associated with the presence of dyspepsia, making the prediction of its appearance challenging. However, the number of medications was associated with its presence, suggesting it could be a function of treatment for AF. Regardless of the specific cause, patients with AF and dyspepsia reported significantly worse health outcomes than patients with $\mathrm{AF}$ and without dyspepsia, emphasizing that the management of dyspepsia among patients with AF should be a greater area of focus.

\section{Acknowledgment}

The authors thank Jan-Samuel Wagner, a consultant to Kantar Health, for his assistance with the literature review. 


\section{Disclosure}

The NHWS is fielded by Kantar Health. Bayer Yakuhin Ltd, purchased access to the NHWS data and funded the analysis and preparation of this manuscript. YK is a paid consultant to Bayer Yakuhin Ltd, for critical discussions on the study analysis, study interpretation, and clinical insights. MD is an employee of Kantar Health. BR and ECYW are employees of Bayer Yakuhin Ltd; KI and J-BB were employees of Bayer Yakuhin Ltd at the time of the study.

\section{References}

1. Inoue H, Fujiki A, Origasa H, et al. Prevalence of atrial fibrillation in the general population of Japan: an analysis based on periodic health examination. Int J Cardiol. 2009;137:102-107.

2. Lip GY, Tse HF. Management of atrial fibrillation. Lancet. 2007;370: 604-618.

3. van den Berg MP, Hassink RJ, Tuinenburg AE, et al. Quality of life in patients with paroxysmal atrial fibrillation and its predictors: importance of the autonomic nervous system. Eur Heart J. 2001;22:247-253.

4. Kang Y, Bahler R. Health-related quality of life in patients newly diagnosed with atrial fibrillation. Eur J Cardiovasc Nurs. 2004;3:71-76.

5. Wolowacz SE, Samuel M, Brennan VK, Jasso-Mosqueda JG, Van Gelder IC. The cost of illness of atrial fibrillation: a systematic review of the recent literature. Europace. 2011;13:1375-1385.

6. Rohrbacker NJ, Kleinman NL, White SA, March JL, Reynolds MR. The burden of atrial fibrillation and other cardiac arrhythmias in an employed population: associated costs, absences, and objective productivity loss. J Occup Environ Med. 2010;52:383-391.

7. Suzuki S, Yamashita T, Otsuka T, et al. Treatment strategy and clinical outcome in Japanese patients with atrial fibrillation. Heart Vessels. 2009;24:287-293.

8. Nakatani Y, Mizumaki K, Nishida K, et al. Anticoagulation control quality affects the D-dimer levels of atrial fibrillation patients. Circ J. 2012;76:317-321.

9. Briere JB, Rossi B, Iwamoto K, Stankus A, DiBonabentura MD. Patient Characteristics and Comorbidities of Patients with Atrial Fibrillation in Japan. Value in Health. 2012; 15: A113.

10. Alonso J, Ferrer M, Gandek B, et al; IQOLA Project Group. Healthrelated quality of life associated with chronic conditions in eight countries: results from the International Quality of Life Assessment (IQOLA) project. Qual Life Res. 2004;13:283-298.

11. LaMori JC, Mody SH, Gross HJ, et al. Dyspepsia and disease burden among patients with atrial fibrillation. Crit Pathw Cardiol. 2012;11:14-19.

12. Liu GG, DiBonaventura MD, Yuan Y, et al. The burden of illness for patients with viral hepatitis C: evidence from a national survey in Japan. Value Health. 2012;15:S65-S71.
13. Charlson ME, Pompei P, Ales KL, MacKenzie CR. A new method of classifying prognostic comorbidity in longitudinal studies: development and validation. J Chronic Dis. 1987;40:373-383.

14. Fukuhara S, Bito S, Green J, Hsiao A, Kurokawa K. Translation, adaptation, and validation of the SF-36 Health Survey for use in Japan. J Clin Epidemiol. 1998;51:1037-1044.

15. Fukuhara S, Ware JE Jr, Kosinski M, Wada S, Gandek B. Psychometric and clinical tests of validity of the Japanese SF-36 Health Survey. J Clin Epidemiol. 1998;51:1045-1053.

16. Reilly MC, Zbrozek AS, Dukes EM. The validity and reproducibility of a work productivity and activity impairment instrument. Pharmacoeconomics. 1993;4:353-365.

17. Mahadeva S, Yadav H, Rampal S, Everett SM, Goh KL. Ethnic variation, epidemiological factors and quality of life impairment associated with dyspepsia in urban Malaysia. Aliment Pharmacol Ther. 2010;31:1141-1151.

18. Malfertheiner P. Current concepts in dyspepsia: a world perspective. Eur J Gastroenterol Hepatol. 1999;11 Suppl 1:S25-S29.

19. Jones RH, Lydeard SE, Hobbs FD, et al. Dyspepsia in England and Scotland. Gut. 1990;31:401-405.

20. Talley NJ, Zinsmeister AR, Schleck CD, Melton LJ. Dyspepsia and dyspepsia subgroups: a population-based study. Gastroenterology. 1992;102:1259-1268.

21. Mahadeva S, Raman MC, Ford AC, et al. Gastro-oesophageal reflux is more prevalent in Western dyspeptics: a prospective comparison of British and South-East Asian patients with dyspepsia. Aliment Pharmacol Ther. 2005;21:1483-1490.

22. Kunz JS, Hemann B, Edwin Atwood J, Jackson J, Wu T, Hamm C. Is there a link between gastroesophageal reflux disease and atrial fibrillation? Clin Cardiol. 2009;32:584-587.

23. Gerson LB, Friday K, Triadafilopoulos G. Potential relationship between gastroesophageal reflux disease and atrial arrhythmias. J Clin Gastroenterol. 2006;40:828-832.

24. Weigl M, Gschwantler M, Gatterer E, Finsterer J, Stöllberger C. Reflux esophagitis in the pathogenesis of paroxysmal atrial fibrillation: results of a pilot study. South Med J. 2003;96:1128-1132.

25. Mahadeva S, Yadav H, Rampal S, Goh KL. Risk factors associated with dyspepsia in a rural Asian population and its impact on quality of life. Am J Gastroenterol. 2010;10:904-912.

26. Wildner-Christensen M, Hansen JM, De Muckadell OB. Risk factors for dyspepsia in a general population: non-steroidal antiinflammatory drugs, cigarette smoking and unemployment are more important than Helicobacter pylori infection. Scand J Gastroenterol. 2006;41:149-154.
Clinical and Experimental Gastroenterology

\section{Publish your work in this journal}

Clinical and Experimental Gastroenterology is an international, peerreviewed, open access journal, publishing all aspects of gastroenterology in the clinic and laboratory, including: Pathology, pathophysiology of gastrointestinal disease; Investigation and treatment of gastointestinal disease; Pharmacology of drugs used in the alimentary tract;

\section{Dovepress}

Immunology/genetics/genomics related to gastrointestinal disease. This journal is indexed on CAS. The manuscript management system is completely online and includes a very quick and fair peer-review system. Visit http://www.dovepress.com/testimonials.php to read real quotes from published authors. 